\title{
Social, Sexual, and Violent Predation: Are Psychopathic Traits Evolutionarily Adaptive?
}

\author{
J. Reid Meloy, PhD, Angela Book, PhD, Ashley Hosker-Field, PhD, \\ Tabitha Methot-Jones, $\mathrm{MA}^{2}$, and Jennifer Roters, $\mathrm{MA}^{2}$
}

\begin{abstract}
The construct of psychopathy is typically viewed as a psychopathology, and more specifically, a severe personality disorder with manifest psychobiological deficiencies. There is an alternative perspective that certain aspects of psychopathy are evolutionarily adaptive, and confer an advantage at both the individual and group level. In this article, we explore the research on psychopathy as it relates to social, sexual, and violent predation to demonstrate that psychopathy provides an adaptive psychobiological template for success. Utilizing Meloy's $(1988,2006)$ ten normative criteria for predatory violence, it appears psychopathy research findings over the past 30 years facilitate four domains of predatory behavior in humans: calmness, rationality, attention, and fantasy.
\end{abstract}

Keywords: psychopathy, predatory violence, adaptation, evolution

$\mathbf{P}$ SYCHOPATHY has TRADITIONALly been viewed as a personality disorder characterized by interpersonal, affective, and behavioral dysfunction (Hare 2003). Hare's model views psychopathy as a two-factor construct: Factor 1 comprises the interpersonal and affective traits, and Factor 2 makes up the social deviance characteristics and behaviors. Factor 1 traits include glibness, superficial charm, grandiosity, manipulation, lack of remorse and empathy, and shallow affect. Factor 2 is associated with the antisocial lifestyle aspects of psychopathy, and includes a need for stimulation, parasitic lifestyle, impulsivity, poor behavioral controls, early behavior problems, adolescent delinquency, and a varied criminal history (Hare 2003). In recent years, empirical work has supported the use of a four-facet model in which Factor 1 is divided into interpersonal (facet 1) and affective (facet 2), and Factor 2 is divided into lifestyle (facet 3) and antisocial (facet 4) (Neumann et al. 2015).

Despite this traditional conceptualization, several researchers have called into question the notion that psychopathy is a disorder, suggesting that the construct may be more accurately viewed as a life history strategy that is evolutionarily adaptive (Barr and Quinsey 2004; Book and Quinsey 2004; Krupp et al. 2013; Mealey 1995; Seto et al. 1997). For example, Krupp and colleagues (2013) concluded that psychopathy did not meet Wakefield's (1992) harmful dysfunction criteria for being a disorder. Wakefield (1992) suggested that to be considered a disorder, the related symptoms must (1) cause harm to the subject or others and (2) result from a psychological mechanism's failure to achieve its intended adaptive purpose. While psychopathy does meet the first requirement, the second requirement does not appear to be met. Krupp and colleagues (2013) argued that, while there are indeed neurobiological differences between psychopaths and nonpsychopaths, differences do not necessarily equal dysfunction; and furthermore, such differences may actually be evolutionarily advantageous.

From this perspective, psychopaths can be seen as interpersonal cheaters, enabling them to benefit cheaply from their interactions with others. This has clear evolutionary advantages, allowing resource procurement and reproductive success with minimal investment. More specifically, in the language of game theory, psychopaths can be seen as being both "cheaters" and "warrior-hawks"; in other words, "cheater-hawks" (Book and Quinsey 2004; Book et al. 2016a). Cheaters use manipulation and deception to exploit the cooperation of others, while warrior-hawks use intimidation and aggression to get what they want (Dawkins 1976). Indeed, researchers have suggested that psychopathic traits are adapted to exploit others (Glenn et al. 2011; Mealey 1995). It is not difficult to imagine that lack of empathy and fear, combined with the tendency to be superficially charming, would enable the successful exploitation of others (Book and Quinsey 2004). Moreover, research has also found that psychopathic traits are correlated with deception in many domains (Seto et al. 1997), and that

\footnotetext{
${ }^{1}$ Department of Psychiatry, University of California, San Diego, La Jolla, California.

${ }^{2}$ Department of Psychology, Brock University, St. Catharines, Ontario, Canada.
} 
psychopaths are more exploitive and aggressive than their nonpsychopathic counterparts (Book et al. 2016a). Empirical findings also indicate that psychopathic traits are associated with the use of intimidation and aggression, and are negatively associated with altruistic behavior (Book and Quinsey 2004; Book et al. 2016a). Because of these consistent relationships, Book and colleagues (2016a) have suggested that psychopathy is an adaptation for social predation. Meloy (2012) reviewed the literature supporting the idea that psychopaths are predators, specifically in their use of instrumental or predatory aggression, and are psychobiologically predisposed for such adaptation through their "predatory acuity" and reduced cognitive load.

The use of predatory violence and aggression among animal species as a means of survival (by hunting for food or prey) has been well established as a normal behavior (Gregg and Siegel 2001; Hinde 1966; Mirsky and Siegel 1994; Ohman 1986). Moreover, this predation has been found to be accompanied by a very specific set of behavioral criteria. According to Meloy (1988a, 1997, 2000a, 2006), there are several criteria that are specifically relevant with respect to predatory violence in humans, in contrast to affective (defensive and reactive) violence. A review of the literature reveals that these characteristics appear to be especially prevalent among psychopaths, suggesting that they are particularly well suited for social predation, ranging from social manipulation and exploitation of others for material gain to planned, homicidal violence, such as serial murder. As such, the primary purpose of this article is to evaluate psychopathy as an adaptation to social, sexual, and violent predation by examining the psychopathy literature through the lens of Meloy's normative theoretical criteria for predatory violence. (Meloy 1988a, 2006).

Table 1 compares forensic criteria originally developed to distinguish between affective and predatory violence (Me-

Table 1. Comparison of Forensic Criteria for Affective and Predatory Violence (Meloy 1988a, 2006)
Affective violence
1. Intense autonomic arousal
2. Subjective experience of emotion
3. Reactive and immediate violence
4. Perceived threat
5. Goal is threat reduction
6. Possible displacement of target
7. Time-limited behavioral sequence
8. Preceded by public posturing
9. Primarily emotional/defensive
10. Altered awareness ${ }^{\mathrm{a}}$
Predatory violence
1. Minimal autonomic arousal
2. No conscious emotion
3. Planned and purposeful violence
4. No imminent perceived threat
5. Variable goals
6. No displacement of the target
7. No time-limited sequence
8. Preceded by private ritual
9. Primarily cognitive/attack
10. Focused awareness ${ }^{\mathrm{a}}$

${ }^{\mathrm{a}}$ Criterion 10 wording has been slightly changed from original formulations. loy 1988a). The criteria have been subsequently elaborated upon (Meloy 2000a, 2006), and have been shown in one study to have excellent interrater reliability (Raine et al. 1998; Kappa=0.86). Affective violence was originally identified in the work of Hess and Brugger (1943) with laboratory cats, and was referred to as "affective defense." The approach utilized electrical stimulation techniques of the cat's brain, and expanded to include the study of predation, or "quiet biting attack" over the next 30 years (Flynn et al. 1970; Wasman and Flynn 1962). Reis organized these findings (1971, 1974), and referred to them as predatory and affective aggression, the latter demonstrating sympathetic arousal of a variety of neuroanatomical pathways, while the former did not. Subsequent research indicated that these were two biologically distinct modes of aggression with both differential neural pathway and neurochemical activations (Gregg and Siegel 2001; McEllistrem 2004). Eichelman (1988, 1992) was the first psychiatrist and researcher to propose distinctive psychopharmacological approaches to these two modes of aggression in humans, with subsequent research supporting his efforts (Meloy and Yakeley 2014).

There are a number of characteristics of psychopathy established in the research, which appear to enhance the tactical success of an individual engaging in social, sexual, and violent predation, and support the normative criteria identified in Table 1.

\section{The Calmness of Predation: Minimal Autonomic Arousal (1), No Conscious Emotion (2), and No Hurry (7)}

Predatory violence is characterized by low autonomic arousal (criteria 1), the absence of emotion, such as anger or fear (criteria 2), and no time-limited behavioral sequence (7). It is hunting behavior. Minimal autonomic arousal and no conscious emotion are also important discriminators between predatory and affective violence (Barratt et al. 1997; Meloy 2006, 2012; Stanford et al. 2003b). Neurochemistry research has found that various neurotransmitters regulate all aggression, including acetylcholine, GABA, dopamine, norepinephrine, serotonin, and some neuropeptides (opioid peptides, substance $\mathrm{P}$, and cholecystokinin). Some of these chemicals potentiate, and others inhibit the two modes of aggression (Meloy 2012; Siegel et al. 2007). Predatory attack in cats is solicited by electrical stimulation of the outside edge of the hypothalamus (perifornical lateral area), the edge and back area of the periacqueductal gray (ventrolateral aspect of the PAG), and the ventral tegmental area. An intriguing finding with direct application to these modes of violence in humans is that there are reciprocal inhibiting pathways between the medial (center) and lateral (outside edge) areas of the hypothalamus in cats. The medial area is activated during affective violence, and the lateral areas are activated during predatory violence. GABA, a suppressing neurotransmitter, is utilized in both modes of violence to inhibit activation in each case (Cheu and Siegel 1998). The evolutionary implication for predation is that the mammal needs to inhibit autonomic arousal as well as disruptive emotional states to be tactically successful in killing its prey-otherwise he will signal his intent. Likewise, in affective violence, intense autonomic arousal and emotional displays, usually anger or fear, will hopefully fend off the threat. Genetic viability, or evolutionary success, would be 
enhanced by strong adaptive capacities to do both modes of violence, as is seen in psychopathic subjects (Blair et al. 2005; Cornell et al. 1996; Meloy 1988a; Raine 2013). If, as suggested, psychopathy is an evolutionary adaptation for social predation, then individuals who exhibit psychopathic traits should also be prone to low autonomic arousal and emotionality. Indeed, research has demonstrated that psychopaths display both of these characteristics.

Studies have repeatedly shown across various contexts that psychopaths tend to demonstrate low levels of autonomic arousal. Hare (1965) found that individuals who exhibit psychopathic traits display decreased arousal during anticipation of punishment. These findings have been replicated through the decades, and are generally characterized as peripheral autonomic hyporeactivity to aversive stimuli (Gacono 2016). Research conducted by Benning and colleagues (2005) found that within a community sample, individuals who exhibited Factor 1 psychopathy traits did not display the anticipated increase in electrodermal activity in response to aversive stimuli-skin conductance is a direct measure of autonomic arousal-thus indicating low autonomic arousal. Further evidence of the low arousal observed among psychopathic individuals can be found in a metaanalysis conducted by Lorber (2004). The research examined the psychophysiology associated with psychopathy during various states of arousal. Results demonstrated that psychopathy was associated with significantly lower resting electrodermal activity, weaker electrodermal reactivity (specific to stimuli with negative valence), and a smaller change in arousal as a function of stimulus presentation. Therefore, across studies, psychopathy does indeed appear to be associated with low arousal, specifically with respect to electrodermal hyporeactivity.

A related line of research has focused on central rather than peripheral CNS activity and the construct of "chronic cortical underarousal." This construct, conceived by Raine (1993), is measured by three biological markers: low skin conductance, low resting heart rate, and theta wave EEG activity. Research has demonstrated, for example, that chronic cortical underarousal in adolescent males is predictive of habitually violent criminality over the subsequent decade, even when controlling for other sociocultural factors (Raine 2013); and the absence of these characteristics protects against criminal behavior, even when raised in a criminogenic environment (Glenn and Raine 2014; Raine et al. 1995). In a study comparing successful and unsuccessful psychopaths, and controls, the successful psychopaths had the lowest resting heart rate, although their skin conductance was the same as the controls-but demonstrated superior executive functioning when compared to the controls (Ishakawa et al. 2001). However, there is still little research on the successful psychopath living in the community, compared to the failed psychopath, which make up the vast majority of subjects in the study of psychopathy (Raine 2013).

Consistent with Meloy's second criterion for predatory violence, "no conscious emotion," research and theory have also demonstrated that psychopaths tend to exhibit a general lack of affect/emotionality, referred to as affective deficiency in Factor 1 (facet 2) of the PCL-R (Hare 2003). One line of research that supports such an emotional disconnection are the theoretical and empirical conclusions that have been drawn with respect to the psychopath's lack of fear. For example, several theoretical perspectives regarding the etiology of psychopathy, including the Low Fear Hypothesis (Lykken 1995), the Dual Process Model (Fowles and Dindo 2009), and the Integrated Emotions Systems Model (Blair 2006), suggest that psychopathy is characterized, in part, by a lack of emotion, and more specifically, by a lack of fear. Several empirical research studies have supported this perspective. For example, research has found that psychopaths exhibit a diminished fearpotentiated startle response when presented with unpleasant or aversive stimuli, a finding that has been interpreted as reflecting low fear, and abnormal emotional processing more generally (Benning et al. 2005; Levenston et al. 2000; Patrick et al. 1993). Recent work has even suggested that psychopaths may actually enjoy fear as evidenced by observed associations between psychopathic traits and positive evaluations of fearrelevant stimuli and personal experiences of fear (Hosker-Field et al. 2016). Fearlessness may be underpinned by the low resting heart rate findings, and research has traced a fearless and uninhibited temperament in childhood, through adolescents who are more insensitive to social stressors, to more aggression in adulthood (Raine 2013; Raine et al. 1998). Much of this research has been conducted on the island of Mauritius, off the African coast, where the absence of a criminogenic environment has allowed for the naturalistic teasing apart of nature and nurture within a stable, multicultural, and nonWestern society (Raine 2013).

The emotional poverty observed among psychopaths is not limited to fear; callousness, a lack of guilt, empathy, and remorse are also included as defining traits of the construct in Factor 1 (facet 2) of the PCL-R (Hare 2003). Meloy (1988a, 2001) discussed these emotions in the context of psychoanalytic theory-feeling states which necessitate whole object representations and their absence suggest that psychopaths live in a presocialized emotional world, wherein others are mentally represented as part objects and not appreciated as whole, real, and separate human beings. Indeed, research does demonstrate that psychopaths do appear to display a lack of concern or regard for distress in others. For example, Pfabigan and colleagues (2015) found that violent offenders, including psychopaths, demonstrated a lack of emotional arousal when witnessing others in pain. Interestingly, despite a diminished physiological response, violent offenders high in psychopathy provided self-report empathy ratings that were indistinguishable from those obtained from a nonpsychopathic community control group. This finding suggests that although psychopaths do not appear to experience emotion in the same capacity as others, they do have intact cognitive understanding of appropriate emotional responses. This may be adaptive with respect to social predation, specifically in regard to the successful deception and manipulation of others. As a lack of conscious emotion is included as a defining characteristic of predatory violence, the lack of fear, empathy, and affect, in general, found among psychopaths may indeed make them more adept at predatory violence. To take this idea further, Siegel and Victoroff (2009), as noted earlier, found GABA inhibition of the medial hypothalamus by the lateral hypothalamus during predatory violence, and hypothesized a neural mechanism in humans, which would support the absence of emotion during predation. Supplementary studies have also found that lower functioning dopaminergic activity increases the risk for violence; such a mechanism would act as a motivating factor in experiencing aggression hedonistically, thus 
accentuating its behaviorally rewarding qualities (Chester et al. 2016). In line with the idea that psychopathic traits are associated with hedonistic aggression, Reidy and colleagues (2011) found that people scoring high on Factor 1 traits were more likely to engage in unprovoked aggression, and were less likely to see violent imagery as unpleasant (Reidy et al. 2011).

Levi and colleagues (2010) hypothesized that executive function and personality tests could differentiate violent from nonviolent criminals, in addition to discriminating between predatory, irritable, and defensive aggression based on criminal history. Predatory (goal directed and unemotional), irritable (anger based), and defensive (fear based) aggression would then activate different brain networks (Levi et al. 2010).

A similar premise is that emotional stimulation could arouse a significant cortical response in psychopaths; however, an interruption in processing emotional faces occurs when the reciprocal functional interaction between the amygdala and neocortex fails to integrate emotion into cognition in individuals with psychopathy (Contreras-Rodríguez et al. 2014). In another study by Prado and colleagues (2015), both primary and secondary psychopathic traits were related to diminished precision in classifying facial affect, where more distinct impairments were apparent in primary psychopathy. Even though primary and secondary psychopathy traits were observed to be associated with discrepancies in dispositional self-control, the results were markedly increased for individuals with secondary psychopathic traits (Prado et al. 2015). In a comprehensive research review, Salekin (2017) reported that there is considerable support in the literature for deficits in facial affect recognition (especially fear), reduced empathy, and an inability to recognize distress in the faces of victims among children with elevated psychopathic traits; he concludes that the specific deficits are unclear. The decreased emotional engagement in subjects across studies, however, was consistently interpreted through the lens of deficiency rather than facilitating the development of predatory skill and success.

The forensic basis for these "calmness" criteria was derived from three sources: (1) interviews of subjects who had committed acts of predatory violence who would consistently answer "nothing" to the question, "How did you feel when you were committing your act of violence?" (2) Observations of surviving witnesses of predatorily violent events, such as mass murders, serial murder, and sexual sadism, who would invariably describe the perpetrator as calm, controlled, and without emotion. (3) The increasing availability of CCTV or other forms of video capturing such predatory crimes, wherein the perpetrator could be observed and judgments made by professionals, concerning his lack of affect and autonomic arousal. Research has confirmed the presence of psychopathic traits, if not severe psychopathy, in individuals upon clinical assessment, who have committed such acts (Dietz et al. 1990; Hempel et al. 1999; Holt et al. 1999; Meloy 1997, 2000; Woodworth and Porter 2002).

\section{The Rationality of Predation: Planning and Preparation (3), Multiple Goals (5), and the Centrality of the Prefrontal Cortex (9)}

If psychopathic individuals are adapted to be predators, they should be instrumentally rational. Indeed, several philosophers have weighed in on the issue of psychopathy and instrumental rationality (as described in Jurjako and Malatesti 2016), and there appears to be disagreement among theorists on two main questions, namely (1) rationality and (2) moral judgment. In terms of rationality, psychopaths are seen as immoral rational agents by sentimentalists (Prinz 2006), while rationalists do not see psychopaths as rational actors (Kennett 2010). On the moral judgment front, externalists tend to view psychopaths as possessing moral understanding, but lacking the motivation to act morally, while internalists see psychopaths as lacking in moral judgment ability and rationality (Sinnott-Armstrong 2014). The authors note that a lack of rationality would pose problems for moral and legal responsibility, a point that is made by Kiehl and Sinnott-Armstrong (2013).

Given the disagreement among theorists, it is useful to examine the research regarding the relationship between psychopathy and rationality. There is some evidence for lack of rationality, including findings that psychopaths make more passive avoidance errors (Lykken 1957), have difficulties with response extinction and reversal (Lapierre et al. 1995; Newman et al. 1987), and show deficits in the Iowa Gambling Task (Bechara et al. 1994). Even so, Jurjako and Malatesti (2016) argue that these are not indications of irrationality, but rather that psychopaths simply are unable to access the relevant information, especially when that information is affectively framed. Interestingly, when affective information is used as the distractor from the task at hand, psychopaths actually perform better than controls. For example, Ly and colleagues (2016) found that psychopathic individuals showed reduced instrumental avoidance in the presence of aversive stimuli, and that their instrumental behavior was not hampered by affective stimuli. The authors concluded that people with psychopathic traits have reduced affective bias, causing them to perform better under certain conditions. Glenn and Raine $(2009,2014)$ suggest that being less affected by social affective cues allows psychopathic individuals to engage in aggressive behavior because these types of cues normally act to reduce the likelihood of aggression. More evidence for incentive-based rationality comes from Bjork and colleagues (2012) who found that people scoring higher on psychopathy showed higher incentive motivation.

Neuroimaging work has also advanced the understanding of the paralimbic system dysfunction model of psychopathy (Kiehl 2006). Psychopaths generally show less affect-related activity than normals in subcortical areas, but appear to do more "emotional" processing in higher cortical, rational, controlled areas of the brain (Kiehl et al. 2001). More recent work has focused upon diminished connectivity between certain areas of the prefrontal cortex (ventral media portion of the PFC) and the amygdala in psychopaths, the "threat sensor" within the limbic portion of the brain (Harenski et al. 2010; Motzkin et al. 2011). Overall attention within the neuroimaging research regarding psychopathy is focusing upon certain portions of the prefrontal cortex and their interaction, or lack thereof, with the amygdala (Anderson and Kiehl 2012; Blair et al. 2005). In one study, for example, conduct-disordered adolescents with callous-unemotional traits were found to have both increased and decreased amygdala connectivity with other areas of the brain, depending upon the subregion of the amygdala studied, and could account for perturbed emotional and attentional differences in psychopathy (Aghajani et al. 2016). Such work continues to generally 
implicate a functional disconnection between the emotional and executive centers of the brain, but also lends support to the theory of "predatory acuity" (Meloy 2012) due to a lessened cognitive load-namely, less stressors such as anxiety, socialized emotions, and threats to attachment-upon the psychopath as he plans and prepares for his predatory activities.

A neuroimaging study conducted by Raine and colleagues (1998) utilized PET (positron emission tomography, a measure of glucose metabolism in the brain) to compare predatory and affective murderers and a control group following a continuous performance task. The affective murderers showed significantly reduced lateral and medial prefrontal activation when compared to the controls, while the predatory murderers did not differ from the controls. Right subcortical measures, a source of negative emotion, were significantly greater in both groups of murderers when compared to controls. The results suggested hypofrontality in the affective murderers - they could not delay their impulses to kill-and the absence of such an impulsivity problem in the predatory killers. Although there are now hundreds of published structural and functional neuroimaging studies involving psychopathic, antisocial, or habitually violent criminals, many of them utilizing noninvasive MRI and fMRI (functional magnetic resonance imaging, a measure of blood oxygenation inferring brain activity), more imaging studies to investigate differences between affectively and predatorily violent subjects, and their severity of psychopathy, need to be done.

The forensic basis for these predatory criteria, especially the planning and preparation and multiple goals, is derived from the extensive research on pathways to violence, more specifically, the degree to which predators develop the intent, mobilize for violence, and plan and prepare for their acts. This work comes from the empirical study of adolescent and adult mass murderers, serial murderers, serial rapists, public figure attackers, and lone actor terrorists (Dietz et al. 1990; Fein and Vossekuil 1999; Gill 2015; Hazelwood and Burgess 1995; Meloy 2000b; Meloy et al. 2004, 2008; Ressler et al 1992; Woodworth and Porter 2002)-all of whom engage in predation - and the theories of those who practice threat assessment and threat management of targeted violence (Calhoun and Weston 2003; Meloy and Hoffmann 2014; Mohandie 2000).

\section{The Dominance of Predation: Its Relationship to Affective Violence}

All the criteria in Table 1 suggest distinctive differences between predatory and affective violence, and the research supports a bimodal relationship between the two modes of violence (Meloy 2006). If psychopathy is an adaptation for social predation, then it should be consistently related to predatory aggression. It is. Many studies have found either full or partial support for the hypothesis that psychopathic individuals engage in predatory (or instrumentally motivated) aggression to a greater frequency than nonpsychopathic criminals (Cornell et al. 1996; Meloy 2012). In fact, Blair and colleagues (2005) wrote, "No biologically based disorder other than psychopathy is associated with an increased risk of instrumental aggression" (p. 155).

Findings continue to substantiate this relationship. Von Borries and colleagues (2012) found that psychopathic traits were positively correlated with instrumental aggression. The relationship is less clear when correlations are examined at the factor or facet level. Several studies have found that the Interpersonal Manipulation facet 1 of Factor 1 is particularly related to instrumental aggression. For instance, in a sample of 65 forensic psychiatric inmates, Laurell and colleagues (2010) found that the interpersonal traits were correlated with instrumentality and severity of aggression. Similarly, Walsh and colleagues (2009) found a positive relationship in a sample of 248 inmates. This relationship has also been found with self-report measures of psychopathic traits. Reidy and colleagues (2007) found that self-reported primary psychopathic traits (akin to Factor 1 traits) were the only significant predictor of the use of shocks against opponents in their "instrumental" condition (i.e., with performance incentive). Primary and secondary (akin to Factor 2) traits were both predictive in the hostile/reactive condition, where there was no performance incentive. Vitacco and colleagues (2010) examined the intersection of psychopathy, instrumental aggression, and criminal reoffending in a sample of youth using the Psychopathy CheckList-Youth Version. The Interpersonal Manipulation facet 1 and Impulsive Lifestyle facet 3 were both correlated with instrumental aggression. Instrumental aggression was negatively correlated with caught reoffending. However, given the planning and predatory nature of instrumental aggression, it is plausible that such actions were less likely to be detected by law enforcement, and therefore did not result in any arrest or prosecution. Declercq and colleagues (2012) examined the relationship between psychopathy and predatory violence in a sample of 82 violent offenders and found that the Interpersonal Manipulation facet 1 was uniquely associated with predatory violence, while the Antisocial Behavior facet 4 was negatively related to the use of predatory violence. This finding is mirrored by a study conducted by Vitacco and colleagues (2006): in a sample of 122 male young offenders, Interpersonal Manipulation was once again correlated positively with predatory aggression, while the relationship with Antisocial Behavior was negative.

The research regarding the relationship between psychopathy and predatory aggression is not always consistent at the construct level. Several studies have not demonstrated a relationship between Factor 1 and predatory aggression. For example, Camp and colleagues (2013) found that it was Factor 2 that related to history of instrumental offenses, and Factor 1 was unrelated to instrumental offense history. It should be noted, however, that the Interpersonal Manipulation facet 1 was positively correlated with instrumental crimes, while the Callous Affect facet 2 was negatively related, which mirrors the findings above on Interpersonal Manipulation being the key relationship with predatory aggression.

Some early research also found that psychopaths engaged in more frequent affective and predatory violence than other criminals (Cornell et al. 1996; Hare and Jutai 1983; Serin 1991; Serin and Amos 1995; Williamson et al. 1987). More recently Flexon and Jamie (2016) found that callous unemotional traits (as measured by the Youth Psychopathy Inventory; Andershed et al. 2002) were associated with both forms of aggression in a sample of youth. The researchers used an anxiety measure to categorize youth as primary or secondary, and it was predicted that youth categorized as secondary would be motivated more by emotions, while 
those categorized as primary would be more instrumental/ predatory. Results found that secondary traits (hostility and high anxiety) showed stronger relationships to both types of aggression than did primary traits (callousness, shallow affect, and lack of anxiety).

As evidenced by some of the inconsistent findings addressed above, although the psychopathic personality is often characterized by proactive (predatory) aggression, some components of psychopathy, usually Factor 2, appear more highly related to reactive (affective) aggression (Cima and Raine 2009). In a study by Woodworth and Porter (2002), homicides committed by psychopathic offenders were significantly more instrumental (predatory) than homicides by nonpsychopaths. It was found that $93.3 \%$ of homicides completed by psychopaths were principally instrumental when contrasted with $48.4 \%$ of the homicides completed by nonpsychopaths (Woodworth and Porter 2002). In a subsequent study of sexual homicides, those committed by psychopaths tended to be more gratuitous and sadistic in their use of violence (Porter et al. 2003).

In an effort to clear up the seeming disagreement in the literature, Blais and colleagues (2014) conducted a metaanalysis on 55 samples $(N=8753)$. Overall psychopathic traits related to both instrumental (predatory) and reactive (affective) aggression. Looking more closely, the interpersonal manipulation facet 1 of Factor 1 showed the strongest relationship with instrumental aggression, while Factor 2 and its facets were most predictive of reactive aggression. The takeaway message from the literature on instrumental aggression is that the interpersonal manipulation traits (facet 1) appear to be most predictive of predatory or instrumental aggression, while the social deviance traits (facet 4) are correlated with more reactive aggression.

Given the predatory nature of instrumental aggression, one might expect to find that people with psychopathic traits are more likely to engage in criminal stalking of victims. However, Reavis and colleagues (2008) found that psychopathic traits tend to be lower in stalkers, although this finding is consistent with the chronic emotional detachment among psychopaths; stalkers tend to be obsessively attached (Meloy 1998). Other researchers have suggested that stalkers are a heterogeneous group. For example, Storey and colleagues (2008) found that stalkers who do have psychopathic traits are more likely to violate a supervision order by continuing to stalk the victim, become more obsessed with the victim, and tend to select victims who are quite vulnerable. The authors suggest that psychopathic stalkers may "use stalking as a form of bullying to enhance their sense of self and ... gratify sadistic desires" (p. 244). Although stalking itself appears to be predatory in nature, a closer look at the research finds that if violence is committed by a stalker, it is usually affective (Meloy 1998), especially if the stalker is a prior sexual intimate of the victim. Predatory violence appears to be most frequent among stalkers of public figures (Meloy et al. 2008). Among all violent stalkers, there appears to be a strong positive correlation between likelihood of affective violence and prior sexual intimacy with the victim (Meloy 2002). Sheridan and Boon (2002) noted that about $13 \%$ of stalkers are sadistic in their law enforcement typology, and considered them long term, high risk, and motivated by control.

The forensic origin of the theory of frequent predation among psychopaths finds its provenance in the hypothesis that psychopaths define their relationships on the basis of dominance and submission, rather than affection (Meloy 1988a). This relational paradigm when understood from an ethological and evolutionary perspective is a predator-prey dynamic, the essential perspective of the warrior-hawk and the hunter (Bailey 1987; Valzelli 1981). Psychoanalytic interpretation lends an object relationship understanding that the primary motivation of the psychopath is to dominate his objects (Meloy 1988a, 1988b, 2001).

\section{The Attention of Predation: Observational or Predatory Acuity}

Meloy (1988a) also proposed that in predation, there is enhanced focus upon the target (criterion 10) and no displacement of the aggression onto a third party (criterion 6). There are multiple studies suggesting that psychopaths are, in fact, less distractible from their goals. Von Borries and colleagues (2012) found that people with psychopathic traits are less affected by socially threatening stimuli. More specifically, they do not seem to avoid social threats, and do not experience personal distress in the presence of such threats. Research also suggests that psychopathy is associated with the ability to maintain focus on goals in the presence of distracters that are peripheral to those goals (Baskin-Sommers et al. 2012; Wolf et al. 2012; Zeier and Newman 2013). Other research has found that a diminished fear-potentiated startle (FPS) response is present in individuals high in psychopathic traits, but only when participants are not forced to focus on the threat (Baskin-Sommers et al. 2011; Newman et al. 2010). Some research suggests that psychopathic traits are associated with the ability to ignore emotional distractions (Mitchell et al. 2006); more granulated research suggests that this ability is contingent on psychopathy subtype. For example, Maes and Brazil (2015) found a negative relationship between the affective components of psychopathy (Factor 1) and the propensity to be distracted by emotional stimuli when the impulsive and antisocial components of psychopathy (Factor 2) were low. Conversely, the researchers found a positive relationship between the affective components of psychopathy and the propensity to be distracted by emotional stimuli when the impulsive and antisocial components of psychopathy were also high. This evidence suggests that the ability to focus when distracters are present may be different, depending on the specific profile of psychopathy examined.

Some research, however, has suggested that psychopathy is associated with deficits in focus. For example, one study found that psychopathy is not associated with the ability to filter out irrelevant information (Mayer et al. 2006), and another study found that the dimensions of psychopathy were associated with disrupted neural activity when emotional distracters were present (Sadeh et al. 2013). Other studies have suggested that the heightened focus of psychopathic individuals can be detrimental. Kosson (1996) found that individuals high in psychopathic traits had difficulty shifting their attention when their focus was engaged. Research also suggests that individuals high in psychopathy experience less breadth in attention, such that these individuals are less able to focus on peripheral features when their attention is taxed (Kosson 1996, 1998; Sadeh and Verona 2008). 
Individuals with psychopathic traits also encounter perceived threat differently than nonpsychopathic individuals (criterion 4 in predatory violence, no imminent perceived threat). Ly and colleagues (2016) performed a study using an affective decision-making task in a sample of violent offenders. Monetary feedback was used to create an incentive. Individuals who scored higher on psychopathy were not as distracted by the presence of affective stimuli, which suggests that affective bias is reduced in psychopathic individuals. Moreover, individuals with psychopathy tend to respond aggressively when confronted with an ego threat. Furthermore, they exhibited this pattern of aggression more strongly than did narcissistic individuals (Cale and $\mathrm{Li}$ lienfeld 2006).

This aggression, however, is a time-limited behavioral sequence and likely affective violence as noted in Table 1; when autonomic arousal wears off, violence ends. It would follow that there are different emotional-attentional problems in impulsive and instrumentally violent offenders due to abnormalities in attentional disengagement from specific types of emotional content (Chen et al. 2015).

A related theory is that of predatory acuity, wherein a lessened cognitive load (anxiety, attachments, and other emotional states) enhances the observation of the predator (Meloy 2012). Such a theory contributes a partial answer to the emotional paradox of psychopathy: if they do not experience empathy, how can they be such exquisite manipulators? The neuroimaging research (Anderson and Kiehl 2012) would support this disconnection between the limbic system and the neocortex in psychopathy, or at least anomalies in the dynamic relationship between subregions of the amygdala and certain areas of the prefrontal cortex in psychopathy, which could serve this adaptive role (Aghajani et al. 2016; Blair et al. 2005). If the psychopath feels less, and is less aroused, his observational acuity of others as potential victims is enhanced.

Although the research to date yields mixed results, there is some support for the association between psychopathic traits and magnified goal-focus, and with the ability to ignore distracters. This goal-focus should enable individuals high in psychopathic traits to focus on predation without having to attend to distracters on the periphery: eyes in the front, meant to hunt; eyes on the side, meant to hide. Conversely, the findings that psychopathy is not associated with the ability to disengage or attend to peripheral distracters could indicate that this hyperfocus is detrimental, as these individuals would be less able to attend to peripheral threats. What is evolutionarily adaptive for the group may be detrimental to the individual. More research is needed.

The forensic origin of these criteria $(10,6$, and 4) came from the knowledge of selective suppression of other stimuli when mammals are hunting their prey (Hernandez-Peon et al. 1956); self-reports, witness reports, and video observations of individuals committing predatory violence; and the stark contrast with affective violence, wherein a defensive response to a threat, intense autonomic arousal, and emotions of anger and/or fear will be accompanied by sometimes gross perceptual distortions, including time slow down, muffled sound, tunnel vision, dissociative states, and memory loss (Artwohl 2002; Honig and Roland 1998; Lewinski 2002).

\section{The Fantasy of Predation: Private and Narcissistic Ritual}

Private ritual, criterion 8, was theorized to account for the narcissistic fueling that was often self-reported by predators before their violence (Meloy 1988a). This was done in a variety of ways, including particular dress, appearance, skill development, amulet wearing, rehearsal fantasy, behavioral tryouts, and other preparation, which had a more ritualistic rather than tactical meaning for the perpetrator. Such reports were also found in the early literature concerning serial murderers and rapists (Ressler et al. 1992; Hazelwood and Burgess 1995). Prentky and colleagues' (1989) was the first study to demonstrate the importance of rehearsal fantasy when comparing serial and single sexual murderers, as did other fantasy-focused research concerning normal and sexual offenders (MacCulloch et al. 1983; Meloy 2000b). Such ritualistic behavior is also commonly observed before prosocial sports activity, which involves instrumental or predatory violence, such as American football, rugby, boxing, and other martial arts. The military also use fantasy as a means to stimulate both identification as an individual warrior and with other soldiers (Gibson 1994; Meloy et al. 2015).

In a set of studies looking at psychopathic traits and sexual fantasy, Visser and colleagues (2015) found that people scoring high on psychopathy were more likely to report fantasies that included anonymous, uncommitted sexual activity lacking in romantic themes. Not only were they more likely to fantasize, but they were also more likely to report having engaged in dominating and deviant sexual activities, even when controlling for self-reported fantasies.

Following this, one might also expect psychopathic individuals to be more likely to engage in romantic revenge. Only two studies have examined the issue of romantic revenge in relation to psychopathic traits. Brewer and colleagues (2015) specifically examined romantic revenge in response to infidelity, and found that narcissism and primary psychopathy (LsrP) predicted the intent to engage in infidelity, as well as perceived likelihood of partner's infidelity. Also, primary psychopathy was the only unique predictor of intention to get revenge on a partner who was deemed to have engaged in infidelity. In a second study, Rasmussen and Boon (2014) found that Machiavellianism and psychopathy were related to a tendency to endorse power and justice goals for revenge, and for seeing the revenge as having been effective.

\section{The Success of Predation: Other correlates of psychopathy}

As mentioned above, a number of researchers have suggested that psychopaths are social predators, using manipulation and aggression to exploit the cooperation of others (e.g., Mealey 1995), an assumption that has been borne out in the literature. Psychopathic individuals are more likely to engage in general antisocial behavior, as well as violent behavior, to achieve their ends (Hare 2003). Hare (2001) described psychopaths as "social predators who charm, manipulate, and ruthlessly plow their way through life, leaving a broad trail of broken hearts, shattered expectations, and empty wallets" in their wake (p. xi), and are "natural born takers" who are skilled at deception. According to Frank (1988), being a successful social predator would necessarily involve at least two skills: (1) being able to interpret a variety of signals related to 
vulnerability to victimization, which would enable successful victim selection, and (2) using social mimicry to appear trustworthy, allowing the successful exploitation of others.

\section{Victim selection}

Early descriptions of psychopaths highlight their exploitive nature (e.g., Cleckley 1941), and Hare (2001) stated that "Psychopaths view any social exchange as a 'feeding opportunity,' a contest or a test of wills in which there can be only one winner. Their motives are to manipulate and take ruthlessly, and without remorse" (p. 145). The association to hunting for food in the animal kingdom is essential in understanding that all predators will attempt to identify and separate the vulnerable from the herd, whether on the African savannahs or the streets of Los Angeles. Empirical research supports this assertion, in that psychopaths do tend to exploit and manipulate others (Jonason and Webster 2012) and use deception across numerous social contexts (Jonason et al. 2014). In addition to being deceptive and manipulative, psychopaths are impulsive and aggressive (Cima and Raine 2009), using such strategies to get what they want from others. Despite attenuated fear and empathy (Hare 2003), people with psychopathic traits seem able to successfully manipulate and charm others (Cleckley 1941; Hare 2003), implying that they are able to use socially relevant information to manipulate the people around them. Supporting this idea, people with psychopathic traits do appear to have insight into the intentions, emotions, and motivations of other people (Richell et al. 2003). Interpreting others' actions and intentions involves knowledge of mental states. Our everyday understanding of others, or "folk psychology" (Stitch and Ravenscroft 1994) is a fundamental resource for introducing meaning to the world around us. This interpretive ability can be viewed as an ability to understand others and ourselves in terms of mental states and has also been called "theory of mind" (Premack and Woodruff 1978), namely, the ability to interpret others' minds in terms of intentional states such as beliefs and desires (Leslie and German 1995). Clearly, Theory of Mind would be valuable in manipulating and deceiving others in a variety of contexts. In one study examining the link between theory of mind and psychopathy in adult offenders, Richell and colleagues (2003) found that adult psychopathic offenders did not demonstrate any impairment deficits in this skill. Furthermore, psychopaths appear to be able to understand what others are feeling and what motivates them to act (Blair et al. 1996), although they do appear to be less responsive to distress signals. They have smaller physiological responses than nonpsychopaths when presented with stimuli displaying distress signals (Blair et al. 1997). The fact that psychopaths are able to understand others' motivations and actions and, yet, are not affected by the usual accompanying feelings has been described by Lorenz and Newman (2002) as the "emotion paradox," and would be inherently useful in being a social predator, allowing for a callous disregard for others, a lack of guilt, and enabling exploitation and aggression without the usual negative emotional consequences. Research suggests that people scoring high on psychopathic traits-both undergraduate students and inmates - are adept at judging vulnerability in individuals unknown to them after watching a short video- taped interaction (Book et al. 2007), as well as being able to accurately pick victims of historical abuse based on their gait alone (Book et al. 2007; Wheeler et al. 2009). In these studies, raters watched short video-clips of targets walking and rated their likelihood of having been victimized. The psychopathic individuals performed significantly better than comparisons.

Psychopathic traits have consistently been found to be related to the use of sexual coercion and manipulation. O'Connell and Marcus (2016), for example, found psychopathic traits to be correlated with many types of sexual coercion. Furthermore, Knight and Guay (2006) found that psychopathic offenders commit significantly more sexual assaults and also report a more positive attitude toward sexually coercive behaviors. Also, in a sample of male and female college students, the Psychopathic Personality Inventory was correlated with positive attitudes toward sexual coercion (O'Connell and Marcus 2016).

\section{Social mimicry}

A second skill that is essential to successful exploitation of others is the ability to charm and manipulate, and to appear trustworthy. Psychopaths not only utilize manipulation and deception more often (Seto et al. 1997) but they also appear to be skilled at it, at least from anecdotal evidence (Hare 2001). Scientific studies investigating this issue include studies on malingering, polygraph studies, and studies examining deceptive impression portrayal. Typically, studies looking at psychopathy and malingering find that psychopathic individuals are no more successful than nonpsychopaths at avoiding detection (e.g., Poythress et al. 2001), although one could legitimately theorize that enhancing one's appearance would be more relevant than malingering in the context of everyday interpersonal situations. A large amount of the research on psychopathy and deception has focused on avoiding detection on the polygraph, and such research has not found any significant differences between psychopaths and controls (e.g., Patrick and Iacono 1989). The problem with this approach lies in its lack of ecological validity. Essentially, one does not usually have a polygraph at one's disposal during interpersonal interactions. Information that would typically be available involves the impression portrayed by each individual, and studies investigating this question have found that psychopathic traits were positively correlated with the ability to deceive. For example, Billings (2004) found that individuals with higher psychopathy scores were better able to deceive naive judges. Furthermore, Book and colleagues (2006) found that individuals who were able to fake in a positive direction on the Holden Psychological Screening Inventory (HPSI; Holden 1996) without being detected by the validity index had significantly higher psychopathy scores than individuals who were caught by the validity index. It would seem, then, that psychopathic traits may enable successful deception in certain contexts (e.g., impression portrayal for personal gain). This begs the question of how psychopaths are able to avoid detection in interpersonal situations. Frank (1988) suggested that successful opportunists would need to appear honest, while availing themselves of opportunities for personal gain, and that opportunists are able to appear trustworthy because their cheating and manipulation are 
masked by feigned emotional displays. Other researchers agree that emotional displays predict future behavior and these displays are socially motivated (e.g., Griffiths 2002). Consistent with this viewpoint is the fact that emotional expressions are used most often in the company of other people, and that they are much more marked in social than in solitary situations (Fridlund 1994). Griffiths (2002) went so far as to say that emotional displays are Machiavellian, in that individuals produce displays of emotion when it is advantageous for them to do so. Recently, Jones (2014) developed mimicry-deception theory to help explain the exploitive tendencies (and success) of psychopathic individuals. He suggested that there is a degree of social mimicry necessary for appearing to be trustworthy, which increases the likelihood of interaction. To determine whether people who score higher on psychopathic traits are better at social mimicry, one study had samples of male students, community members, and inmates feign emotions that tend to be lacking in individuals with psychopathic traits, namely fear and remorse (Book et al. 2016b). Posed fear expressions and feigned remorse stories were both judged as more genuine in individuals scoring higher on measures of psychopathy, including self-report measures and the Psychopathy Checklist Revised (PCL-R; Hare 2003), suggesting enhanced emotional mimicry.

\section{Conclusions}

We have attempted to build a scientific basis for psychopathy providing an adaptive psychobiological template for social, sexual, and violent predation by illustrating how the findings within the developing science of psychopathy empirically support the normative theoretical criteria for predatory violence (Meloy 1988a). Table 2 documents four domains of scientific research concerning psychopathy, which we have detailed, and their relationship to the ten criteria for predation.

In addition, we have explored other scientific characteristics found in psychopathy which enhance the probability of successful social predation, whether overtly violent or not. These include both victim selection as well as social mimicry. Although it is reassuring to view psychopathy as a deficiency, and perhaps a psychopathology that one day will be treatable, there is virtually no evidence to date that it is a disorder for which there is a fix (Meloy and Yakeley 2014), and no positive outcome data concerning treatment of severely psychopathic individuals utilizing randomized controlled tri-

Table 2. The Domains of Predation Supported By the Research on PSychopathy

\begin{tabular}{l} 
Calmness of predation \\
Minimal autonomic arousal \\
No conscious emotion \\
No time-limited behavioral sequence \\
Rationality of predation \\
Planned and purposeful \\
Variable goals \\
Primarily cognitive/attack \\
Attention of predation \\
No imminent perceived threat \\
No target displacement \\
Focused awareness \\
Fantasy of predation \\
Preceded by private ritual \\
\hline
\end{tabular}

als. It may be instead that psychopathy is a genotype within our species, which is phenotypically expressed to different degrees depending on culture, and confers a genetic advantage. It thus survives, although a survival that is characterized by the mark of Cain, and will continue to do so throughout history. A more clear-eyed view of its adaptive characteristics, especially in the context of predation, may keep others safe.

\section{Author Disclosure Statement}

No competing financial interests exist.

\section{References}

Aghajani M, Colins OF, Klapwijk ET, et al. (2016). Dissociable relations between amygdala subregional networks and psychopathy trait dimensions in conduct-disordered juvenile offenders. Hum Brain Mapp. 37, 4017-4033.

Andershed H, Kerr M, Stattin H, Levander S. (2002). Psychopathic traits in non-referred youths: A new assessment tool. In Psychopaths: Current International Perspectives. E. Blaauw, \& L. Sheridan, eds. (Elsevier: The Hague) pp. 131-158.

Anderson N, Kiehl K. (2012). The psychopath magnetized: Insights from brain imaging. Trends Cogn Sci. 16, 52-60.

Artwohl A. (2002). Perceptual and memory distortion during officerinvolved shootings. FBI Law Enforcement Bull. 71, 19-24.

Bailey K. (1987). Human Paleopsychology. (Lawrence Erlbaum Assoc., Hillsdale, NJ.).

Barr KN, Quinsey VL. (2004). Is psychopathy a pathology or a life strategy? Implications for social policy. In Evolutionary Psychology, Public Policy, and Personal Decisions. C. Crawford \& C. Salmon, eds. (Erlbaum, Hillsdale, NJ) pp. 293-317.

Barratt E, Stanford M, Kent T, Felthous A. (1997). Neuropsychological and cognitive psychophysiological substrates of impulsive aggression. Biol Psychiatry. 41, 1045-1047.

Baskin-Sommers A, Curtin JJ, Li W, Newman JP. (2012). Psychopathyrelated differences in selective attention are captured by an early event-related potential. Pers Disord. 3, 370-378.

Baskin-Sommers AR, Curtin JJ, Newman JP. (2011). Specifying the attentional selection that moderates the fearlessness of psychopathic offenders. Psychol Sci. 22, 226-234.

Bechara A, Damasio A, Damasio H, Anderson S. (1994). Insensitivity to future consequences following damage to human prefrontal cortex. Cognition. 50, 7-15.

Benning SD, Patrick CJ, Iacono WG. (2005). Psychopathy, startle blink modulation and electrodermal reactivity in twin men. Psychophysiology. 42, 753-762.

Billings F. (2004). Psychopathy and the ability to deceive. ETD Collection for University of Texas, El Paso. Paper AAI3125565. http://digitalcommons.utep.edu/dissertations/AAI3125565 (accessed May 10, 2018).

Bjork J, Chan G, Hommer D. (2012). Psychopathic tendencies and mesolimbic recruitment by cues for instrumental and passively-obtained rewards. Biol Psychiatry. 89, 408-415.

Blair J, Mitchell D, Blair K. (2005). The Psychopath: Emotion and the Brain. (Blackwell Publishing, Malden, MA)

Blair RJR, Jones L, Clark F, Smith M. (1997). The psychopathic individual: A lack of responsiveness to distress cues? Psychophysiology. 34, 192-198.

Blair RJR, Sellars C, Strickland I, et al. (1996). Theory of mind in the psychopath. J Forensic Psychiatry. 7, 15-25.

Blair RJR. (2006). Subcortical brain systems in psychopathy: The amygdala and associated structures. In Handbook of Psychopathy. Christopher J Patrick, ed., (The Guilford Press, New York), pp. 292-312 
Blais J, Solodukhin E, Forth AE. (2014). A meta-analysis exploring the relationship between psychopathy and instrumental versus reactive violence. Criminal Justice Behav. 41, 797-821.

Book A, Methot T, Gauthier N, et al. (2016b). The mask of sanity revisited: Psychopathic traits and affective mimicry. Evol Psychol Sci. 1, 91-102.

Book A, Methot-Jones T, Blais J, et al. (2016a). Psychopathic traits and the cheater-hawk hypothesis. J Interpersonal Violence. DOI: $10.1177 / 0886260516669168$.

Book AS, Holden RR, Starzyk KB, et al. (2006). Psychopathic traits and experimentally induced deception in self-report assessment. Pers Individ Differences. 41, 601-608.

Book AS, Quinsey VL, Langford D. (2007). Psychopathy and the perception of affect and vulnerability. Criminal Justice Behav. 34, 531-544.

Book AS, Quinsey VL. (2004). Psychopaths: Cheaters or warriorhawks?. Pers Individ Differences. 36, 33-45.

Brewer G, Hunt D, James G, Abell L. (2015). Dark triad traits, infidelity and romantic revenge. Pers Individ Differences. 83, 122-127.

Cale EM, Lilienfeld SO. (2006). Psychopathy factors and risk for aggressive behavior: A test of the "threatened egotism" hypothesis. Law Hum Behav. 30, 51-74.

Calhoun F, Weston S. (2003). Contemporary Threat Management. (Specialized Training Services, San Diego).

Camp JP, Skeem JL, Barchard K, et al. (2013). Psychopathic predators? Getting specific about the relation between psychopathy and violence. J Consul Clin Psychol. 81, 467-480.

Chen CY, Muggleton NG, Juan CH. (2015). Attentional biases to emotion in impulsive and instrumental violent offenders: An eventrelated potential study. J Forensic Psychiatry Psychol. 26, 202-223.

Chester DS, DeWall CN, Derefinko KJ, et al. (2016). Looking for reward in all the wrong places: Dopamine receptor gene polymorphisms indirectly affect aggression through sensation-seeking. Soc Neurosci. 11, 487-494.

Cheu J, Siegel A. (1998). GABA receptor mediated suppression of defensive rage behavior elicited from the medial hypothalamus of the cat: The role of the lateral hypothalamus. Brain Res. 783, 293-304.

Cima M, Raine A. (2009). Distinct characteristics of psychopathy relate to different subtypes of aggression. Pers Individ Differences. 47, 835-840.

Cleckley H. (1941). The Mask of Sanity. (Mosby, St. Louis, MO).

Contreras-Rodríguez O, Pujol J, Batalla I, et al. (2014). Disrupted neural processing of emotional faces in psychopathy. Soc Cogn Affect Neurosci. 9, 505-512.

Cornell DG, Warren J, Hawk G, et al. (1996). Psychopathy in instrumental and reactive violent offenders. J Consult Clin Psychol. 64, 783-790.

Dawkins R. (1976). The Selfish Gene. London: Oxford.

Declercq F, Willemsen J, Audenaert K, Verhaeghe P. (2012). Psychopathy and predatory violence in homicide, violent and sexual offenses: Factor and facet relations. Legal Criminol Psychol. 17, 59-74.

Dietz P, Hazelwood R, Warren J. (1990). The sexually sadistic criminal and his offenses. Bull Am Acad Psychiatry Law. 18, 162-178.

Eichelman B. (1988). Toward a rational pharmacotherapy for aggressive and violent behavior. Hosp Commun Psychiatry. 1, 31-39.

Eichelman B. (1992). Aggressive behavior from laboratory to clinic: Quo vadit? Arch Gener Psychiatry. 49, 488-492.

Fein RA, Vossekuil BV. (1999). Assassination in the United States: An operational study of recent assassins, attackers, and near-lethal approachers. J Forensic Sci. 44, 321-333.

Flexon JL. (2016). Callous-unemotional traits and differently motivated aggression: An examination of variants in a noninstitutionalized sample. Youth Violence Juvenile Justice. [Epub of print ahead]; DOI: 10.1177/1541204015577000
Flynn J, Vanegas H, Foote W, Edwards S. (1970). Neural Mechanisms Involved in Cat's Attack on a Rat: The Neural Control of Behavior. (Academic Press, New York.).

Fowles DC, Dindo L. (2009). Temperament and psychopathy: A dual pathway model. Curr Direct Psychol Sci. 18, 179-183.

Frank RH. (1988). Passions within Reason. (Norton, New York.).

Fridlund A. (1994). Human Facial Expression: An Evolutionary View. (Academic Press, San Diego.).

Gacono CB. (Ed.). (2016). The Clinical and Forensic Assessment of Psychopathy: A Practitioner's Guide (2nd edition.). (Lawrence Erlbaum and Associates, Mahwah, NJ).

Gibson J. (1994). Warrior Dreams. (Hill and Wang, New York.).

Gill P. (2015). Lone Actor-Terrorists: A Behavioural Analysis. (Routledge, New York.).

Glenn A, Raine A. (2014). Psychopathy: An Introduction to Biological Findings and Their Implications. (New York University Press, New York.).

Glenn AL, Kurzban R, Raine A. (2011). Evolutionary theory and psychopathy. Aggression Violent Behav. 16, 371-380.

Glenn AL, Raine A. (2009). Psychopathy and instrumental aggression: Evolutionary, neurobiological, and legal perspectives. Int J Law Psychiatry. 32, 253-258.

Gregg T, Siegel A. (2001). Brain structures and neurotransmitters regulating aggression in cats: Implications for human aggression. Prog Neuropsychopharmacol Biol Psychiatry. 25, 91-140.

Griffiths PE. (2002). Basic emotions, complex emotions, Machiavellian emotions. philsci-archive.pitt.edu/604/ (accessed May 7, 2018).

Hare R. (1965). Psychopathy, fear arousal, and anticipated pain. Psychol Rep. 16, 499-502.

Hare RD, Jutai JW. (1983). Criminal history of the male psychopath: Some preliminary data. In Prospective Studies of Crime and Delinquency. K. T. Van Dusen \& S. A. Mednick, eds. (KluwerNijhoff Publishing, Dordrecht, The Netherlands.), pp. 225-236

Hare RD. (2001). Psychopaths and their nature: Some implications for understanding human predatory violence. In Violence and Psychopathy. A. Raine \& J. Sanmartin, eds. (Kluwer, New York, NY.), pp. 5-34.

Hare RD. (2003). Manual for the Revised Psychopathy Checklist (2nd edition.). (Multi-Health Systems, Toronto, ON, Canada.).

Harenski CL, Harenski KA, Shane MS, Kiehl KA. (2010). Aberrant neural processing of moral violations in criminal psychopaths. J Abnorm Psychol. 119, 863-874.

Hazelwood R, Burgess A, eds. (1995). Practical Aspects of Rape Investigation (2nd edition.). (CRC Press, New York.).

Hempel A, Meloy JR, Richards T. (1999). Offender and offense characteristics of a nonrandom sample of mass murderers. J Am Acad Psychiatry Law. 27, 213-225.

Hernandez-Peon R, Scherrer H, Jouvet M. (1956). Modification of electrical activity in cochlear nucleus during "attention" in unanesthetized cats. Science. 123, 331-332.

Hess WR, Brugger M. (1943). Das subkortikale zentrum der affektiven abwehrreaktion. Helv Physiol Pharmacol Acta. 1, 33-52.

Hinde R. (1966). Animal Behaviour: A Synthesis of Ethology and Comparative Psychology. (McGraw-Hill, New York.).

Holden RR. (1996). Holden Psychological Screening Inventory. (Multi-Health Systems, North Tonawanda, NY.).

Holt S, Meloy JR, Strack S. (1999). Sadism and psychopathy in violent and sexually violent offenders. J Am Acad Psychiatry Law. 27, 23-32.

Honig A, Roland J. (1998). Shots fired. Officer involved. The Police Chief. 1-5.

Hosker-Field AM, Gauthier NY, Book AS. (2016). If not fear, then what? A preliminary examination of psychopathic traits and the Fear Enjoyment Hypothesis. Pers Individ Differences. 90, 278-282. 
Ishakawa SS, Raine A, Lencz T, Bihrle S, Lacasse L. (2001). Autonomic reactivity and executive functions in successful and unsuccessful criminal psychopaths from the community. J Abnorm Psychol. 110, 423-432.

Jonason PK, Webster GD. (2012). A protean approach to social influence: Dark Triad personalities and social influence tactics. Pers Individ Differences. 52, 521-526.

Jonason PK, Weeb S, Li NP, Jackson C. (2014). Occupational niches and the Dark Triad traits. Pers Individ Differences. 69, 119-123.

Jones D. (2014). Predatory personalities as behavioral mimics and parasites: Mimicry-deception theory. Perspect Psychol Sci. 9, 445451.

Jurjako M, Malatesti L. (2016). Instrumental rationality in psychopathy: Implications from learning tasks. Philos Psychol. 29, 717-731.

Kennett J. (2010). Reasons, emotion, and moral judgment in the psychopath. In Responsibility and Psychopathy: Interfacing Law, Psychiatry and Philosophy. Luca Malatesti \& John McMillan, eds. London: (Oxford University Press), p. 17.

Kiehl K, Sinnott-Armstrong W. (2013). Handbook of Psychopathy and Law. (Oxford University Press, New York.).

Kiehl KA, Smith AM, Hare RD, et al. (2001). Limbic abnormalities in affective processing by criminal psychopaths as revealed by functional magnetic resonance imaging. Biol Psychiatry. 50, 677684.

Kiehl KA. (2006). A cognitive neuroscience perspective on psychopathy: Evidence for paralimbic system dysfunction. Psychiatry Res. 142, 107128.

Knight RA, Guay JP. (2006). The role of psychopathy in sexual coercion against women. In Handbook of Psychopathy. C. J. Patrick Ed., (Guilford Press, New York, NY).

Kosson DS. (1996). Psychopathy and dual-task performance under focusing conditions. J Abnorm Psychol. 105, 391-400.

Kosson DS. (1998). Divided visual attention in psychopathic and nonpsychopathic offenders. Pers Individ Differences. 24, 373-391.

Krupp DB, Sewall LA, Lalumière ML, et al. (2013). Psychopathy, adaptation, and disorder. Front Psychol. 4, 139.

Lapierre D, Braun CMJ, Hodgins S. (1995). Ventral frontal deficits in psychopathy: Neuropsychological test findings. Neuropsychologia. 33, 139-151.

Laurell J, Belfrage H, Hellstrom A. (2010). Facets on the psychopathy checklist screening version and instrumental violence in forensic psychiatric patients. Criminal Behav Ment Health. 20, 285-294.

Leslie A, German T. (1995). Knowledge and ability in "theory of mind": One-eyed overview of a debate. In Mental simulation: Evaluations and Applications. A. Stone and M. Davies, eds., (Blackwell Publishers, Oxford), pp. 123-150.

Levenston GK, Patrick CJ, Bradley MM, Lang PJ. (2000). The psychopath as observer: Emotion and attention in picture processing. J Abnorm Psychol. 3, 373-385.

Levi MD, Nussbaum DS, Rich JB. (2010). Neuropsychological and personality characteristics of predatory, irritable, and nonviolent offenders: Support for a typology of criminal human aggression. Criminal Justice Behav. 37, 633-655.

Lewinski B. (2002). Stress reactions related to law enforcement encounters. Police Marksman. 27, 23-28.

Lorber MF. (2004). Psychophysiology of aggression, psychopathy and conduct problems: A meta-analysis. Psychol Bull. 130, 531-552.

Lorenz AR, Newman JP. (2002). Short report: Utilization of emotion cues in male and female offenders with antisocial personality disorder: Results from a lexical decision task. J Abnorm Psychol. 111, 513-516.

Ly V, von Borries AKL, Brazil IA, et al. (2016). Reduced transfer of affective value to instrumental behavior in violent offenders. $J$ Abnorm Psychol. 125, 657.
Lykken DT. (1957). A study of anxiety in the sociopathic personality. J Abnorm Soc Psychol. 55, 6-10.

Lykken DT. (1995). The Antisocial Personalities. (Lawrence Erlbaum Associates, Publishers, Hillsdale, NJ.).

MacCulloch M, Snowden P, Wood P, Mills H. (1983). Sadistic fantasy, sadistic behaviour and offending. Br J Psychiatry. 143, 20 29.

Maes JH, Brazil IA. (2015). Distraction from cognitive processing by emotional pictures: Preliminary evidence for an association with interactions between psychopathy-related traits in a non-clinical sample. Pers Individ Differences. 75, 53-58.

Mayer AR, Kosson D, Bedrick E. (2006). Neuropsychological implications of selective attentional functioning in psychopathic offenders. Neuropsychology. 20, 614-624.

McEllistrem J. (2004). Affective and predatory violence: A bimodal classification system of human aggression an violence. Aggression Violent Behav. 10, 1-30.

Mealey L. (1995). The sociobiology of sociopathy: An integrated evolutionary model. Behav Brain Sci. 18, 523-599. This paper was reprinted in 1997 in The Maladapted Mind, edited by Simon BaronCohen, and published by Erlbaum/Taylor- Francis.

Meloy JR, Hempel A, Gray T, et al. (2004). A comparative analysis of North American adolescent and adult mass murderers. Behav Sci Law. 22, 291-309.

Meloy JR, Hoffmann J, eds. (2014). Int Handbook of Threat Assessment. (Oxford Univ. Press, New York.).

Meloy JR, Mohandie K, Knoll J, Hoffmann J. (2015). The concept of identification in threat assessment. Behav Sci Law. 33, 213-237.

Meloy JR, Sheridan L, Hoffmann J, eds. (2008). Stalking, Threatening, and Attacking Public Figures: A Psychological and Behavioural Analysis. (Oxford Univ. Press, New York.).

Meloy JR, Yakeley J. (2014). Antisocial personality disorder. In Treatments of Psychiatric Disorders, 5th edition. G. Gabbard, ed. (Am Psychiatric Publishing, Washington, DC), pp. 1015-1034.

Meloy JR. (1988a). The Psychopathic Mind: Origins, Dynamics, and Treatment. (Aronson, Northvale, NJ.).

Meloy JR. (1988b). Violent and homicidal behavior in primitive mental states. J Am Acad Psychoanal. 16, 381-394.

Meloy JR. (1997). Predatory violence during mass murder. J Forensic Sci. 42, 326-329.

Meloy JR. (2000a). Violence Risk and Threat Assessment. (Specialized Training Services, San Diego, CA.).

Meloy JR. (2000b). The nature and dynamics of sexual homicide: An integrative review. Aggression Violent Behav. 5, 1-22.

Meloy JR. (2001). The Mark of Cain. (The Analytic Press, Hillsdale, NJ.).

Meloy JR. (2002). Stalking and violence. In Stalking and Psychosexual Obsession. J. Boon \& L. Sheridan, eds. (Wiley, London), pp. 105-124.

Meloy JR. (2006). The empirical basis and forensic application of affective and predatory violence. Aust NZ J Psychiatry. 40, 539-547.

Meloy JR. (2012). Predatory violence and psychopathy. In Psychopathy and Law. Hakkanen-Nyholm, H. \& Nyholm, J., eds. (Wiley and Sons, London), pp. 159-175.

Meloy JR. ed. (1998). The Psychology of Stalking: Clinical and Forensic Perspectives. (Academic Press, San Diego.).

Mirsky A, Siegel A. (1994). The neurobiology of violence and aggression. In Understanding and Preventing Violence, Volume 2: Biobehavioral Influences. Reiss A., Miczek K. \& Roth J. eds. (National Academy Press, Washington, DC). pp. 59-111

Mitchell DG, Richell RA, Leonard A, Blair RR. (2006). Emotion at the expense of cognition: Psychopathic individuals outperform controls on an operant response task. J Abnorm Psychol. 115, 559-566.

Mohandie K. (2000). School Violence Threat Management. (Specialized Training Services, San Diego.). 
Motzkin J, Neuman J, Kiehl K, Koenigs K. (2011). Reduced prefrontal connectivity in psychopathy. J Neurosci. 31, 17348-17357.

Neumann C, Hare RD, Pardini D. (2015). Antisociality and the construct of psychopathy: Data from across the globe. J Pers. 83, 678-692.

Newman JP, Curtin JJ, Bertsch JD, Baskin-Sommers AR. (2010). Attention moderates the fearlessness of psychopathic offenders. Biol Psychiatry. 67, 66-70.

Newman JP, Patterson CM, Kosson DS. (1987). Response perseveration in psychopaths. J Abnorm Psychol. 96, 145-148.

O'Connell D, Marcus D. (2016). Psychopathic personality traits predict positive attitudes toward sexually predatory behaviors in college men and women. Pers Individ Differences. 94, 372-376.

Ohman A. (1986). Face the beast and fear the face: Animal and social fears as prototypes for evolutionary analyses of emotion. Psychophysiology. 23, 123-145.

Patrick CJ, Bradley MM, Lang PJ. (1993). Emotion in the criminal psychopath: Startle reflex modulation. J Abnorm Psychol. 102, 8292.

Patrick CJ, Iacono WG. (1989). Psychopathy, threat, and polygraph accuracy. J Appl Psychol. 74, 347-355.

Pfabigan DM, Seidel E, Wucherer AM, et al. (2015). Affective empathy differs in male offenders with high- and low-trait psychopathy. J Pers Disord. 29, 42-61.

Porter S, Woodworth M, Earle J, et al. (2003). Characteristics of sexual homicides committed by psychopathic and nonpsychopathic offenders. Law Hum Behav. 27, 459-470.

Poythress NG, Edens JF, Watkins MM. (2001). The relationship between psychopathic personality features and malingering symptoms of major mental illness. Law Hum Behav. 25, 567-582.

Prado CE, Treeby MS, Crowe SF. (2015). Examining relationships between facial emotion recognition, self-control, and psychopathic traits in a non-clinical sample. Pers Individ Differences. 80, 22-27.

Premack D, Woodruff G. (1978). Does the chimpanzee have a theory of mind?. Behav Brain Sci. 1, 515.

Prentky R, Burgess A, Rokous F, et al. (1989). The presumptive role of fantasy in serial sexual homicide. Am J Psychiatry. 146, 887-891.

Prinz J. (2006). The emotional basis of moral judgments. Philos Explorations. 9, 29-43.

Raine A, Meloy JR, Bihrle S, et al. (1998). Reduced prefrontal and increased subcortical brain functioning assessed using positron emission tomography in predatory and affective murderers. Behav Sci Law. 16, 319-332.

Raine A, Venables P, Williams M. (1995). High autonomic arousal and electrodermal orienting at age 15 years as protective factors against criminal behavior at age 29 years. Am J Psychiatry. 152, 1595-1600

Raine A. (1993). The Psychopathology of Crime. (Academic Press, San Diego.).

Raine A. (2013). The Anatomy of Violence. (Random House, New York.).

Rasmussen K, Boon S. (2014). Romantic revenge and the Dark Triad: A model of impellance and inhibition. Pers Individ Differences. 56, 51-56.

Reavis JA, Allen EK, Meloy JR. (2008). Psychopathy in a mixed gender sample of adult stalkers. J Forensic Sci. 53, 1214-1217.

Reidy DE, Shelley-Tremblay JF, Lilienfeld SO. (2011). Psychopathy, reactive aggression, and precarious proclamations: A review of behavioral, cognitive, and biological research. Aggression Violent Behav. 16, 512-524.

Reidy DE, Zeichner A, Miller JD, Martinez MA. (2007). Psychopathy and aggression: Examining the role of psychopathy factors in predicting laboratory aggression under hostile and instrumental conditions. J Res Pers. 41, 1244-1251.

Reis D. (1971). Brain monoamines in aggression and sleep. Clin Neurosurg. 18, 471-502.
Reis D. (1974). Central neurotransmitters in aggression. Res Publ Assoc Res Nervous Ment Dis. 52, 119-148.

Ressler R, Burgess A, Douglas J. (1992). Sexual Homicide: Patterns and Motives. (Free Press, New York.).

Richell RA, Mitchell DGV, Newman C, et al. (2003). Theory of mind and psychopathy: Can psychopathic individuals read the "language of the eyes"? Neuropsychologia. 41, 523-526.

Sadeh N, Spielberg JM, Heller W, et al. (2013). Emotion disrupts neural activity during selective attention in psychopathy. Soc Cogn Affect Neurosci. 8, 235-246.

Sadeh N, Verona E. (2008). Psychopathic personality traits associated with abnormal selective attention and impaired cognitive control. Neuropsychology. 22, 669-680.

Salekin R. (2017). Research review: What do we know about psychopathic traits in children? J Child Psychol Psychiatry. 58, $1180-1200$

Serin RC, Amos NL. (1995). The role of psychopathy in the assessment of dangerousness. Int J Law Psychiatry. 18, 231-238.

Serin RC. (1991). Psychopathy and violence in criminals. J Interpersonal Violence. 6, 423-431.

Seto MC, Khattar NA, Lalumière ML, Quinsey VL. (1997). Deception and sexual strategy in psychopathy. Pers Individ Differences. 22, 301-307.

Sheridan L, Boon J. (2002). Stalking typologies: Implications for law enforcement. In Stalking and Psychosexual Obsession. J. Boon \& L. Sheridan, eds. (Wiley, London.), pp. 63-82.

Siegel A, Bhatt S, Bhatt R, Zalcman S. (2007). The neurobiological bases for development of pharmacological treatments of aggressive disorders. Curr Neuropharmacol. 5, 135-147.

Siegel A, Victoroff J. (2009). Understanding human aggression: New insights from neuroscience. Int J Law Psychiatry. 32, 209215

Sinnott-Armstrong W. (2014). Do psychopaths refute internalism? In Being Amoral: Psychopathy and Moral Incapacity. Schramme Thomas, ed. (Cambridge, MIT Press.), pp. 187-208.

Stanford M, Houston R, Mathias C, et al. (2003b). Characterizing aggressive behavior. Assessment. 10, 183-190.

Stitch S, Ravenscroft R. (1994). What is folk psychology? Cognition 50, 447-468.

Storey J, Hart S, Meloy JR, Reavis J. (2008). Psychopathy and stalking. Law Hum Behav [Epub ahead of print]; DOI: 10.1007/ s10979-008-9149-5

Valzelli L. (1981). Psychobiology of Aggression and Violence. (Raven Press, New York.).

Visser BA, DeBow V, Pozzebon JA, et al. (2015). Psychopathic sexuality: The thin line between fantasy and reality. J Pers. 83, 376388.

Vitacco MJ, Neumann CS, Caldwell MF, et al. (2006). Testing factor models of the Psychopathy Checklist: Youth Version and their association with instrumental violence. J Pers Assess. 87, 74-83.

Vitacco MJ, Neumann CS, Caldwell MF. (2010). Predicting antisocial behavior in high-risk male adolescents: Contributions of psychopathy and instrumental violence. Criminal Justice Behav. 37, 833-846.

Von Borries L, Volman I, de Bruijn E, et al. (2012). Psychopaths lack the automatic avoidance of social threat: Relation to instrumental aggression. Psychiatry Res. 200, 761-766.

Wakefield J. (1992). The concept of mental disorder. On the boundary between biological facts and social values. Am Psychol. 47, 373388.

Walsh Z, Swogger M, Kosson DS. (2009). Psychopathy and instrumental violence: Facet level relationships. J Pers Disord. 23, 416-424.

Wasman M, Flynn J. (1962). Directed attack elicited from hypothalamus. Arch Neurol. 27, 635-644. 
Wheeler S, Book A, Costello K. (2009). Psychopathic traits and perceptions of victim vulnerability. Criminal Justice Behav. 36, 635648.

Williamson SE, Hare RD, Wong S. (1987). Violence: Criminal psychopaths and their victims. Can J Behav Sci. 19, 454-462.

Wolf RC, Carpenter RW, Warren CM, et al. (2012). Reduced susceptibility to the attentional blink in psychopathic offenders: Implications for the attention bottleneck hypothesis. Neuropsychology. 26, 102-109.

Woodworth M, Porter S. (2002). In cold blood: Characteristics of criminal homicides as a function of psychopathy. J Abnorm Psychol. $111,436$.
Zeier JD, Newman JP. (2013). Feature-based attention and conflict monitoring in criminal offenders: Interactive relations of psychopathy with anxiety and externalizing. J Abnorm Psychol. 122, 797-806.

Address correspondence to: J. Reid Meloy, PhD Department of Psychiatry University of California, San Diego La Jolla, CA 92037

E-mail: reidmeloy@gmail.com 